\title{
La evaluación multicriterio en la ubicación de las ventas ambulantes en Tibasosa, Boyacá, Colombia
}

\author{
Luis Felipe Fajardo Pineda* \\ Andrés Fernando Pava Vargas**
}

Fecha de recepción: 25 de junio de 2020

Fecha de aprobación: 24 de febrero de 2021

Resumen: Este artículo presenta una evaluación con múltiples criterios de alternativas de ubicación para el ejercicio de la venta ambulante en el municipio de Tibasosa, Colombia. El objetivo principal fue identificar la localización estable que más se adaptara a las necesidades de desarrollo productivo de los vendedores informales, en armonía con las demás dinámicas del territorio -sectores económicos, relaciones sociales, aspectos culturales, espaciales, administrativos, entre otras-. Para ello, se aplicó la metodología de evaluación multicriterio (EMC), en la cual se consideraron diversas variables o atributos ligados a la ordenación o ubicación del espacio y se aplicaron a un número específico de las alternativas o posibles locaciones. La investigación se basó en información primaria (entrevistas, encuestas y mesas de trabajo), análisis de normas legales (Esquema de Ordenamiento Territorial) y en estudios específicos para cada caso (radio de distancia, volúmenes peatonales y costeo de intervenciones). Como resultado, se identificó que el parqueadero de la casa cural es el lugar con mayor correspondencia con el objetivo propuesto, pues fue la alternativa con el mayor puntaje de valoración normalizada de los criterios $(0,136)$. Así, en este artículo se propone una metodología de gran pertinencia para emprender procesos de política pública local que permitan identificar la ubicación idónea para las actividades de venta ambulante en un territorio.

Palabras clave: venta ambulante, evaluación multicriterio, economía informal, economía alternativa, política pública.

Clasificación JEL: E26, J50, J71, J81, J88, O17, R23, R28, R38.

Cómo citar:

Fajardo Pineda, L. \& Pava Vargas A. (2021). La evaluación multicriterio en la ubicación de las ventas ambulantes en Tibasosa, Boyacá, Colombia. Apuntes del Cenes, 40(72). Págs. 151 - 179.

\footnotetext{
* Administrador público y economista. Miembro del Grupo Interdisciplinario de Investigación en Modernización y Administración de lo Público (GRIMAP) de la Escuela Superior de Administración Pública (ESAP). luisfajardo@esap.edu.co iD http://orcid.org/0000-0001-6250-7980

** Economista. Magíster (C) en Economía. Profesor auxiliar de la Escuela de Economía, Universidad Pedagógica y Tecnológica de Colombia UPTC. andres.pava@uptc.edu.co (iD https://orcid.org/0000-0001-6743-5074. Contacto de correspondencia.
} 


\title{
The multi-criteria evaluation in the location of street vendors in Tibasosa, Boyacá, Colombia
}

\begin{abstract}
This paper presents an evaluation with multiple criteria of alternative locations for street vending in the municipality of Tibasosa, Colombia. The main objective was to identify the stable location that best suits the productive development needs of informal vendors, in harmony with the other dynamics of the territory -economic sectors, social relations, cultural, spatial and administrative aspects, among others. For this, the Multi-Criteria Evaluation method (MCE) was applied, in which various variables or attributes on space regulations were considered and applied to a specific number of the eventual locations. The research was based on primary information (interviews, surveys and work tables), legal analysis (Territorial Planning Scheme) and on specific studies for each case (distance radius, pedestrian volumes and cost of interventions). As a result, it was identified that the Priest House Parking is the place with the highest correspondence with the proposed objective, since it was the alternative with the highest standardized assessment score of the criteria (0.136). Thus, the article proposes a methodology of great relevance to undertake local public policy processes, in order to identify the ideal location for street vending activities in a territory.
\end{abstract}

Keywords: street vending, multi-criteria evaluation, informal economy, alternative economy, public policy. 


\section{INTRODUCCIÓN}

La venta ambulante responde a un problema estructural del mercado de trabajo, específicamente el de tipo urbano y de las economías en vías de desarrollo: la falta de oportunidades laborales. Empero, como esta actividad comercial no reporta registros mercantiles ni celebra contratos laborales, su carácter informal hace que sus actores sean vulnerables al rechazo social; además, con fundamento en la misión de la política pública, esta actividad se cataloga como una problemática amplia y progresiva que obliga a las administraciones locales, en la búsqueda e implementación de estrategias de solución, a enfrentarse con una dificultad nada fácil de superar: apoyar la generación de condiciones apropiadas para el ejercicio del proyecto productivo de los vendedores ambulantes y propiciarles un ambiente laboral con criterios de dignidad y formalidad, pero preservando, al mismo tiempo, el capital patrimonial, arquitectónico y cultural de la localidad, con el fin de favorecer el interés general sobre el espacio público.
Lo anterior significa que la actividad comercial informal no puede ejercerse en cualquier lugar, puesto que se debe velar por la protección de la integridad y la destinación al uso común del espacio público. Para el caso colombiano, la protección del espacio público está contemplada en el artículo 82 de la Constitución Política de 1991 y en los artículos 139 y 140 de la Ley 1801 de 2016 (Código Nacional de Policía y Convivencia).

Con respecto al municipio en estudio, de acuerdo con la Alcaldía Municipal de Tibasosa (2019), la venta ambulante ha sido ocasionada por el crecimiento demográfico y la poca capacidad del territorio para generar nuevos puestos formales, lo que ha llevado a que se convierta en una fuente de ingresos que posibilita la manutención a ciertas familias tibasoseñas.

No obstante, la actividad comercial informal en Tibasosa también ha estado acompañada de otros factores, como el progreso de la actividad turística, lo que ha permitido que los vendedores ambulantes conjeturen una 
potencial demanda para sus productos. Igualmente, y a raíz de la vocación agropecuaria del municipio, los productores agropecuarios han utilizado la venta ambulante como un canal de oferta de sus mercancías; además, las dinámicas de distribución de la población rural y la inmigración de algunas víctimas del conflicto armado han hecho que estas poblaciones encuentren empleo por medio de la actividad comercial informal; y dada su ubicación geográfica, habitantes de municipios cercanos han visto en Tibasosa una oportunidad para generar empleo informal. Ahora bien, es importante mencionar que el Parque Principal se ha convertido en el lugar en donde se ha ido concentrando la actividad comercial ambulante (Alcaldía Municipal de Tibasosa, 2019).

Esta dinámica descrita de la venta ambulante en el municipio de Tibasosa ha generado conflictos con los demás actores vinculados: administración municipal, comerciantes formales, habitantes e incluso turistas. Por eso, teniendo en cuenta lo anterior, el objetivo del presente documento consiste en identificar la ubicación más conveniente para el desarrollo de la venta ambulante, que garantice una alternativa laboral solvente para los comerciantes y que permita la armonía con las demás dinámicas sociales del municipio, mediante el desarrollo cuantitativo de una técnica de evaluación multicriterio, aplicable a las condiciones socioeconómicas del municipio.
Para lograr el objetivo planteado, el documento se ha estructurado de la siguiente manera: en la primera sección se expone la revisión literaria relacionada con el objeto de investigación; en la segunda sección se describe la forma como se aplicó la evaluación multicriterio a la investigación; en las secciones tercera y cuarta se comparten y discuten los resultados obtenidos, respectivamente; y en la última se presenta la conclusión.

\section{LITERATURA}

De acuerdo con Delgado et al. (2008), el vendedor ambulante se define como aquel vendedor informal que se desplaza por las calles de mayor flujo de transeúntes o peatones sin tener un espacio fijo e invirtiendo un mínimo capital; además, se caracteriza porque su demanda es pasiva, en razón a que es creada a partir de la insistencia y oportunidad del vendedor. Bhowmik (2005) clasifica al vendedor ambulante de la siguiente forma: es estacionario, cuando ocupa espacio en los pavimentos o en otros espacios públicos o privados; y es móvil, cuando vende sus productos movilizándolos mediante vehículos (motorizados o no) o canastos.

Policastro y Rivero (s.f.) afirman que la actividad comercial de estos vendedores es una respuesta alternativa de subsistencia, ante la implementación de políticas económicas que han dirigido a las economías a ser más aperturistas y flexibles; circunstancias que han hecho 
que el trabajo se vuelva precario y que las tasas de informalidad y desocupación tiendan al alza. En ese sentido, la venta ambulante se relaciona con la denominada economía alternativa, la cual es definida como:

una economía dentro de la cual los actores (1) se esfuerzan por evitar los efectos de la creación de valor económico que dañan a la sociedad o la naturaleza, (2) rechazan la separación de las esferas social y económica, (3) perciben y aceptan su responsabilidad por sus actividades sociales y económicas y las consecuencias de estas actividades en los ámbitos social y natural, y (4) intentan participar en formas nuevas o revitalizadas de práctica socioeconómica. (Haase et al., 2018, p. 57)

Estos actores, desde las perspectivas de Gramsci (1971), Spivak (2000), Green (2002), Sarkar y Kundu (2018), se consideran como subalternos, es decir, aquellas personas que hacen parte de las clases humildes: campesinos, artesanos, sirvientes, aldeanos, entre otros; sin educación y marginados por la hegemonía social y económica (De Soto et al., 1986; Bromley, 2000; Bhowmik, 2010).

Para el caso latinoamericano, Ghersi (1997) dice que los vendedores ambulantes han ayudado a poblar las ciudades de la región. Aun así, son vendedores informales porque, pese a que sus objetivos son lícitos -son, ante todo, comerciantes-, deben usar medios ilícitos-incumplimiento de las regulaciones legales, leyes laborales, pago de impues- tos- ya que no tienen otra alternativa de subsistencia. En últimas, esta población de origen humilde, quiere trabajar legalmente, pero no puede, a causa de las grietas instauradas por la legalidad (De Soto et al., 1986; Ghersi, 1997).

Adicional a la falta de oportunidades laborales formales, otros factores que inciden sobre la venta ambulante tienen que ver con el aumento de los costos para el establecimiento y la operación de negocios propios en la formalidad, y el crecimiento de empresas flexibles y dinámicas - lo cual hace alusión a la tercerización, outsourcing o subcontratación-, a raíz de las nuevas demandas de otras empresas, el estilo de vida y las necesidades actuales de las personas (Castañeda \& García, 2007).

Estos factores, en efecto, influyen en que la economía informal sea notable, es decir, el panorama en donde las unidades productivas no están registradas o no existen contratos laborales que garanticen beneficios, derechos y protección social a los trabajadores (Feige, 1990). Este fenómeno tomó protagonismo dentro del campo económico a partir de la década de 1970, como consecuencia de la modernización de la agricultura y el apogeo de la industrialización y, simultáneamente, de la urbanización en los países en vías de desarrollo. Derivado de los anteriores hechos, en dichos países también se comenzó la implementación y discusión del empleo formal (Bhowmik, 2010). 
El estudio de Hart (1973), en concordancia con Portes y Haller (2004), Bhowmik (2010) y Godfrey (2011), es precursor sobre el tema de investigación en consideración, pues al examinar la situación de la comercialización (ambulante) en Accra (capital de Ghana), descubrió cuatro características de la informalidad económica. Aquellas características son (Hart, 1973; citado por Bhowmik, 2010):

- Bajos niveles de cualificación, puesto que en la informalidad no se requiere de especialización por el bajo nivel tecnológico'1.

- Fácil acceso, debido a que, producto de la característica anterior, no existen obstáculos, en sí, para insertarse en la informalidad.

- Empleos con baja paga, en vista de la baja cualificación exhibida (su producto marginal es exiguo, desde el enfoque neoclásico).

- Fuerza laboral mayoritariamente inmigrante, en razón a que la población inmigrante, al no ser generalmente cualificada ${ }^{2}$, solo encuentra empleos informales.

Martínez et al. (2017) indican que, principalmente, cuatro escuelas de pensamiento han analizado el fenómeno de la economía informal: la legalista (Becker, 2004), que considera la infor- malidad económica como una respuesta a los excesos de procedimientos, regulaciones y costos -en términos de dinero, esfuerzo y tiempo-, establecidos por el Estado al aparato productivo; la voluntarista (Chen, 2012), en la que se da énfasis a la decisión intencionalmente tomada por los individuos para participar en la informalidad, puesto que perciben más beneficios en contraste con los adquiridos en la formalidad; la estructuralista (Portes \& Halles, 2004), la cual justifica que la informalidad se ha vuelto un sector complementario y subordinado de la estructura formal de la economía, a causa de los cambios adoptados en las condiciones laborales; y la dualista (Chen, 2012), que explica la informalidad como un sector generador de ingresos para los individuos con recursos limitados 3 .

Por otro lado, Castañeda y García (2007) mencionan que son cinco las grandes aproximaciones en literatura sobre el tema: la subjetivista o voluntarista (Maloney, 2004), la paradójica (Portes \& Halles, 2004), la ortodoxa (De Soto et al., 1986; De Soto, 2000), la institucional y la estructuralista (Cimoli, Primi \& Pugno, 2006).

Estas escuelas difieren con respecto al carácter residual o no de la informalidad económica, así como sobre los

1 Al no ser alto el nivel tecnológico, los empleos en la informalidad son intensivos en mano de obra, lo que hace que dicha situación de la economía absorba el excedente de oferta laboral -que, por cierto, no es cualificada-.

2 Ha salido de su territorio de origen, en búsqueda de mejores oportunidades. Sin embargo, no le resulta fácil cumplir este objetivo, pues sus competencias laborales son básicas.

3 De lo descrito, las escuelas estructuralista y dualista guardan relación porque, entendiéndose que la economía está estructurada por dos sectores (enfoque dual), donde uno es intensivo en capital y productivo (sector moderno), y el otro no (sector tradicional) -por el contrario, es abundante en mano de obra (y no cualificada)-, este último sector ha tenido que desenvolverse bajo la informalidad (enfoque estructural) (Jiménez, 2012). 
factores relevantes en cada caso. Así, mientras las dos primeras destacan el carácter no residual (y voluntario) de la informalidad, las tres últimas consideran que es un refugio frente a las dificultades o la imposibilidad de acceder al empleo (por cuenta propio o por terceros) en la formalidad. (Castañeda \& García, 2007, pp. 55-56)

En relación con los factores de cada aproximación (o escuela), Castañeda y García (2007) han sintetizado y complementado que en la paradójica falta capacidad institucional para controlar el cumplimiento de la norma, las estructuras sociales y los recursos culturales de la población; en la ortodoxa, a causa de la excesiva e ineficiente estructura normativa, los individuos empiezan a inquietarse con el espíritu empresarial, por medio del autoempleo; en la institucional se ha tendido a poner en práctica estrategias para reducir los costos laborales; y en la estructuralista, los países en vías de desarrollo no logran encarar plenamente la informalidad, porque la economía formal es estructuralmente modesta.

\section{Según Bromley (2000), y Stan y} Stefanescu (2018), la venta ambulante manifiesta puntos a favor y en contra. Como ventajas, representa una importante fuerza laboral, lo que contribuye al crecimiento económico; sus trabajadores cuentan con una enorme capacidad de adaptación; ofrece una considerable flexibilidad en horarios y niveles de actividad; da vida a las calles aburridas, con puestos coloridos, disfraces y mercancías; y puede presenciar e informar delitos, además de proporcionar otro tipo de información a los traseúntes (direcciones, por ejemplo).

Entre las desventajas (Bromley, 2000; Stan \& Stefanescu, 2018) se encuentran las siguientes:

- No posibilita la recaudación de impuestos y de aportes a la seguridad social, lo que dificultaría la financiación del proceso de calidad de vida.

- Crea competencia desleal al no asumir costos comerciales legales (impuestos, aportes a seguridad social, entre otros).

- Reconoce condiciones laborales precarias por no estar dentro del marco normativo laboral y comercial, lo que lleva a que la actividad comercial sea confundida, en ocasiones, como de tipo delictivo, sometida al acoso, soborno, extorsión y represión.

- Crea una brecha entre las competencias del recurso humano con respecto a la actividad comercial en discusión: como la venta ambulante no exige competencias sofisticadas, impide que la población involucrada mejore sus competencias laborales.

- A raíz de su condición informal, no puede recurrir al sector financiero (formal) para solicitar préstamos. Por el contrario, se encuentra obligada a aceptar fuentes de financiación inseguras (por ejemplo, el sistema "gota a gota"). 
- Los vendedores ambulantes no se distribuyen uniformemente por la ciudad, sino que se concentran en pocos lugares -los de mayor afluencia-, provocando congestión vehicular o de peatones, y hasta posibles accidentes de tráfico. A su vez, esa distribución espacial ocasiona conflictos sobre el uso del espacio público y puede generar contaminación (estética o auditiva), así como promoción del desorden.

- La inadecuada manipulación de alimentos y bebidas (la venta ambulante ofrece este tipo de productos) puede acarrear problemas de salud pública.

Dado que la venta ambulante es una problemática de carácter urbano, resulta pertinente relacionar el proceso de urbanización con la informalidad económica. Elgin y Oyvat (2013) demuestran que, a través de la evidencia empírica para 152 países durante un periodo de nueve años (de 1999 a 2007), en las primeras fases de la urbanización, la informalidad (medida en términos porcentuales del PIB) es alta (en promedio, el $40 \%$ del PIB) en respuesta a factores adicionales como la baja carga fiscal, la elevada tasa de desempleo y el bajo nivel de capital urbano. Situación contraria acontece cuando las economías se encuentran en fases avanzadas de la urbanización -la informalidad es baja (el $15 \%$ del PIB, en promedio)-. Así pues, los anteriores resultados ilustran la relación de las variables examinadas como una $\mathrm{U}$ invertida.

En términos regionales, los países latinoamericanos y caribeños exhiben los más altos índices de informalidad económica, independientemente de las distintas fases de la urbanización (en promedio, aproximadamente el $33 \%$ del PIB), en comparación con otros países en vías de desarrollo, como son los de Oriente Medio y de África septentrional4 (Elgin \& Oyvat, 2013).

La venta ambulante ha abordado, dentro de sus prácticas, relaciones de poder entre el Estado y los vendedores, centradas principalmente en el conflicto sobre el espacio público. Recientemente, dos desarrollos claves han hecho comprender este conflicto (Tafti, 2020): el primero, rechazar la visión que sitúa el conflicto en la fisura entre formalidad e informalidad, y el segundo, no enmarcar el conflicto en función de un análisis dicotomizado entre Estado y vendedores ambulantes.

Por lo tanto, en lugar de estigmatizar y sancionar a los vendedores ambulantes, lo ideal es que los gobiernos formulen acciones de política pública, con el fin de mejorar las condiciones socieconómicas de los vendedores y fomentar relaciones amenas con su entorno. Estas políticas permitirían, consecuentemente, el cumplimiento de los Objetivos

$4 \quad$ En términos promediados, el $25 \%$ del PIB en las primeras fases de la urbanización y el $18 \%$ del PIB en fases avanzadas. 
de Desarrollo Sostenible (ODS) 8 y $11^{5}$, para el caso de la venta ambulante (Deore \& Lathia, 2019).

Aprovechar adecuadamente el espacio público es garantía para superar las restricciones que tienen los vendedores ambulantes en la estructura socioeconómica:

Entre todos los espacios públicos, las calles emergen como las más públicas. Las calles son motores de actividades económicas, centros sociales y plataformas para el compromiso cívico. Rompen las divisiones socioeconómicas y fomentan la cohesión social. La planificación, el diseño y la gestión de mejores espacios públicos se han convertido en importantes debates globales. (Deore \& Lathia, 2019, p. 138)

La reubicación es una estrategia de aprovechamiento adecuado del espacio público para gestar condiciones de productividad. Donovan (2004) indica que los vendedores ambulantes reubicados en mercados especializados tienen mayores posibilidades de desarrollar un proyecto productivo solvente, en contraste con los que son ubicados en mercados indiferenciados. La aglomeración de mercados informales, organizados y regulados por entidades públicas u organizaciones productivas, promueven externalidades económicas positivas como el incremento de la demanda y la disminución de costos. Sin embargo, la estrategia expone la siguiente limitante: no es fácil trasladar su clientela (Bromley, 2000).

\section{METODOLOGÍA}

La determinación de la ubicación idónea para situar de forma estable a los vendedores ambulantes del municipio de Tibasosa se lleva a cabo en la presente investigación mediante una evaluación multicriterio (EMC), técnica muy idónea para abordar integralmente este tipo de fenómenos públicos. Es una herramienta de gran utilidad para alcanzar los fines propuestos, por medio de un análisis holístico de las tendencias sociales del territorio, lo que posibilita involucrar un significativo número de elementos o variables de análisis (criterios), los cuales pueden ser cuantificables o no. La EMC forma parte de una tendencia académica e institucional que analiza los fenómenos sociales de forma multivariable y supera la linealidad de un criterio único para determinar la conveniencia entre alternativas (Romero \& Charles, 1997).

La forma metodológica de expresar un proceso de EMC se sintetiza mediante una matriz, tal como se observa en la Tabla 1. En esta se evidencia el procedimiento, el cual contrasta un número indefinido de alternativas (1) con varios criterios (j). 
Tabla 1. Matriz de evaluación

\begin{tabular}{|c|c|c|c|c|c|c|c|}
\hline & \multicolumn{6}{|c|}{ Alternativas (I) } \\
\hline & & 1 & 2 & 3 & 4 & $\ldots$ & 1 \\
\hline 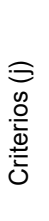 & $\begin{array}{c}1 \\
2 \\
3 \\
4 \\
5 \\
\ldots \\
\text { j }\end{array}$ & & & Xjl & & & \\
\hline
\end{tabular}

Fuente: Gómez y Barredo (2005, p. 53).

En general, se ha elegido esta metodología a fin de identificar la ubicación más idónea para el desarrollo integral del territorio tibasoseño, que brinde a los vendedores ambulantes un escenario propicio para realizar su proyecto económico y que además garantice la armonía con los demás ámbitos sociales del municipio. Con el uso de la EMC se asegura la rigurosidad técnica que requiere el fenómeno, entendiendo que la dinámica del comercio informal puede alterar de forma significativa otros elementos del territorio, los cuales corresponden a sectores económicos, relaciones sociales, aspectos culturales, espaciales, administrativos, entre otros. El proceso se describe a continuación.

\section{Identificación de alternativas}

La selección de la ubicación adecuada para la actividad comercial en discusión ha tenido en cuenta unas alternativas claramente definidas por el equipo decisor. Estas corresponden a soluciones, candidatos o posibles escenarios que son consideradas en el estudio, al tener cierta probabilidad o adaptabilidad con el objetivo planteado. Esto se realizó mediante un proceso de optimización, en el que se compararon diferentes posibilidades de ubicación a partir del análisis de sus características diferenciales.

Según lo define Romero (1996), las alternativas deben corresponder a dos principios: ser disjuntas y exhaustivas. Ello implica que corresponden a un conjunto finito, es decir, no puede tener otras posibilidades intermedias. Además, deben ser susceptibles de observación, caracterización y medición, de acuerdo con los criterios que sean definidos por el equipo decisor.

A pesar de esto, otro tipo de elecciones como las de alcance social o aquellas en las que las posibilidades son incalculables, se deben hacer siguiendo los siguientes criterios definidos por Romero (1996): 
- Formular con claridad el problema por resolver con la aplicación de la EMC.

- Enumerar y especificar con claridad las causas del fenómeno problemático.

- Sintetizar las soluciones.

Dada la naturaleza del fenómeno, para este caso fue necesario un proceso de selección y priorización, en el entendido de que estrictamente cualquier lugar del municipio se puede considerar como alternativa de análisis. En el mismo proceso se siguió el procedimiento técnico de relevancia, a través de un campo epistemológico interdisciplinar (conocimientos en administración pública, economía, ordenamiento territorial, trabajo social, movilidad y gestión ambiental); se revisó el material cartográfico con el que cuenta la Alcaldía y con funcionarios de este ente territorial se hicieron visitas de campo a probables lugares que posibilitaron la aplicación del estudio, en el marco de la problemática y objetivos planteados. Las alternativas seleccionadas por el equipo decisor están contenidas en la Tabla 2.

Tabla 2. Alternativas de ubicación para la venta ambulante, municipio de Tibasosa

\begin{tabular}{ccc}
\hline N. ${ }^{\circ}$ & Alternativa & Dirección \\
\hline 1 & Parque Principal & Carrera 9, entre calles 3 y 4 \\
2 & Interior casa de la Alcaldía & Carrera 10, entre calles 3 y 4 \\
3 & Escuela - zona frontal & Carrera 10, entre calles 2 y 3 \\
4 & Parqueadero - casa cural & Carrera 10, entre calles 2 y 3 \\
5 & Escuela - zona posterior & Carrera 11, entre calles 2 y 3 \\
6 & Pesebre - zona frontal & Carrera 10, entre calles 4 y 5 \\
7 & Pesebre - zona posterior & Carrera 11, entre calles 4 y 5 \\
8 & Canchas de Santillana & Autopista (carrera 2), con calle 4 \\
9 & Coliseo & Autopista (carrera 2), salida a Duitama \\
10 & Parque Ecológico & Calle 2 sur \\
\hline
\end{tabular}

Fuente: elaboración propia con base en estudio de selección de alternativas.

\section{Criterios de decisión}

Gómez y Barredo (2005) anotan que los criterios en procesos decisionales de ordenación o ubicación del espacio se clasifican en dos tipos: factores y limitantes.
- Factores: se definen como criterios o variables susceptibles de una valoración cuantitativa en escala continua. Corresponden a atributos observados de la alternativa, los cuales se pueden medir en escala continua.

- Limitantes: corresponden a atributos de identificación o posesión de las alternativas, es decir, son variables 
que evalúan si las alternativas tienen o no una determinada característica. Estas se evalúan mediante una escala binaria, representada en valores como Sí o No, 1 o 0 , X o Y, entre otras formas según la metodología usada para su análisis.
Generalmente, la definición de los criterios, sean factores o limitantes, obedece al planteamiento de los objetivos estipulados anteriormente por el decisor o equipo decisor. Así, los criterios establecidos son los exhibidos en la Tabla 3; sus fuentes de información son de tipo primario, dado que se han levantado de un ejercicio investigativo de campo.

Tabla 3. Criterios de decisión para la ubicación de la venta ambulante, municipio de Tibasosa

\begin{tabular}{|c|c|c|c|c|}
\hline N. ${ }^{\circ}$ & Criterio & $\begin{array}{l}\text { Tipo de } \\
\text { criterio }\end{array}$ & $\begin{array}{c}\text { Fuente de } \\
\text { información }\end{array}$ & Descripción fuente de información \\
\hline 1 & $\begin{array}{l}\text { Propiedad del } \\
\text { terreno del } \\
\text { municipio }\end{array}$ & Limitante & $\begin{array}{l}\text { Secretaría de } \\
\text { Hacienda de } \\
\text { Tibasosa }\end{array}$ & $\begin{array}{l}\text { Mediante el uso de la base datos del registro predial } \\
\text { del municipio, se identificaron las alternativas o } \\
\text { predios que son de propiedad de la Alcaldía. }\end{array}$ \\
\hline 2 & $\begin{array}{l}\text { Adecuación del } \\
\text { uso del suelo, } \\
\text { según el Esquema } \\
\text { de Ordenamiento } \\
\text { Territorial (EOT) }\end{array}$ & Limitante & $\begin{array}{l}\text { Análisis EOT, } \\
\text { municipio de } \\
\text { Tibasosa }\end{array}$ & $\begin{array}{l}\text { Se identificaron los usos del suelo de cada una de } \\
\text { las alternativas o predios, a partir de lo reportado } \\
\text { por el EOT del municipio (Acuerdo } 020 \text { del } 2000 \text {, } \\
\text { modificado por Acuerdo } 009 \text { del 2011). Se identificó } \\
\text { la correspondencia del uso normativo o potencial } \\
\text { de cada localización con la actividad comercial } \\
\text { pretendida. }\end{array}$ \\
\hline 3 & $\begin{array}{l}\text { Capital cultural, } \\
\text { arquitectónico } \\
\text { o ambiental }\end{array}$ & Limitante & $\begin{array}{l}\text { Evaluación } \\
\text { propia del equipo } \\
\text { investigador }\end{array}$ & $\begin{array}{l}\text { De acuerdo con el EOT y la evaluación de la } \\
\text { Secretaría de Cultura del municipio, se determinó } \\
\text { si las alternativas correspondían a sitios de interés } \\
\text { cultural, arquitectónico o ambiental. }\end{array}$ \\
\hline 4 & $\begin{array}{l}\text { Costos de } \\
\text { adecuación } \\
\text { del terreno }\end{array}$ & Factor & $\begin{array}{l}\text { Secretaría de } \\
\text { Infraestructura } \\
\text { Pública y } \\
\text { Movilidad de } \\
\text { Tibasosa }\end{array}$ & $\begin{array}{l}\text { La Secretaría de Infraestructura Pública y Movilidad } \\
\text { de Tibasosa realizó un costeo de las adecuaciones de } \\
\text { infraestructura que debería recibir cada alternativa o } \\
\text { predio para el desarrollo de la actividad comercial, el } \\
\text { cual se calculó a partir de unas disposiciones mínimas } \\
\text { que se proyectaron para el lugar. }\end{array}$ \\
\hline 5 & $\begin{array}{l}\text { Cantidad de } \\
\text { establecimientos } \\
\text { formales cercanos }\end{array}$ & Factor & $\begin{array}{l}\text { Secretaría de } \\
\text { Hacienda de } \\
\text { Tibasosa }\end{array}$ & $\begin{array}{l}\text { Mediante el uso de la base de datos del Impuesto } \\
\text { de Industria y Comercio, así como el trabajo de } \\
\text { identificación del equipo de la Secretaría de Hacienda, } \\
\text { se ubicaron en un mapa los establecimientos } \\
\text { comerciales del casco urbano del municipio. } \\
\text { Posteriormente se trazó un radio de } 70 \text { metros } \\
\text { desde cada una de las alternativas o predios y se } \\
\text { contabilizaron los establecimientos dentro de estos. }\end{array}$ \\
\hline 6 & $\begin{array}{c}\text { Volumen peatonal } \\
\text { y vehicular }\end{array}$ & Factor & $\begin{array}{l}\text { Estudio de } \\
\text { conteos } \\
\text { peatonales y } \\
\text { vehiculares }\end{array}$ & $\begin{array}{l}\text { Se realizó un estudio de volúmenes peatonales para } \\
\text { cada una de las alternativas de análisis. Los conteos } \\
\text { de los volúmenes peatonales y vehiculares se llevaron } \\
\text { a cabo en todos los lugares o alternativas, de forma } \\
\text { paralela en un día domingo, dentro de una franja } \\
\text { horaria comprendida entre las 11:00 a.m. y 12:00 m., } \\
\text { por ser el dia de la semana y el horario con mayor } \\
\text { movilidad de turistas en el municipio de Tibasosa. } \\
\text { Del resultado ponderado para cada alternativa se } \\
\text { le asignó un } 70 \% \text { al volumen peatonal y un } 30 \% \text { al } \\
\text { volumen vehicular. }\end{array}$ \\
\hline
\end{tabular}


Continuación Tabla 3

\begin{tabular}{|c|c|c|c|c|}
\hline N. ${ }^{\circ}$ & Criterio & $\begin{array}{l}\text { Tipo de } \\
\text { criterio }\end{array}$ & $\begin{array}{c}\text { Fuente de } \\
\text { información }\end{array}$ & Descripción fuente de información \\
\hline 7 & $\begin{array}{l}\text { Percepción de } \\
\text { los vendedores } \\
\text { ambulantes }\end{array}$ & Factor & $\begin{array}{l}\text { Entrevistas de } \\
\text { caracterización } \\
\text { socioeconómica } \\
\text { de vendedores } \\
\text { ambulantes }\end{array}$ & $\begin{array}{l}\text { Resultados de las entrevistas de caracterización } \\
\text { socioeconómica aplicadas a vendedores ambulantes } \\
\text { del municipio de Tibasosa. En ellas se consultó la } \\
\text { percepción a través de pregunta cerrada con escala } \\
\text { de favorabilidad frente a cada alternativa (Muy alta, } \\
\text { Alta, Media, Baja y Muy baja). }\end{array}$ \\
\hline 8 & $\begin{array}{l}\text { Percepción de la } \\
\text { comunidad general }\end{array}$ & Factor & $\begin{array}{l}\text { Encuestas de } \\
\text { percepción } \\
\text { de comunidad } \\
\text { general }\end{array}$ & $\begin{array}{l}\text { Resultados de la encuesta de percepción de la } \\
\text { comunidad general del municipio de Tibasosa. En } \\
\text { ella se consultó la percepción a través de pregunta } \\
\text { cerrada con escala de favorabilidad frente a cada } \\
\text { alternativa (Muy alta, Alta, Media, Baja y Muy baja). }\end{array}$ \\
\hline 9 & $\begin{array}{l}\text { Posibilidad de } \\
\text { generación de } \\
\text { externalidades } \\
\text { ambientales } \\
\text { o sociales }\end{array}$ & Limitante & $\begin{array}{l}\text { Evaluación } \\
\text { propia del equipo } \\
\text { investigador }\end{array}$ & $\begin{array}{l}\text { Se evaluaron tres externalidades: } \\
\text { Ambiental: de acuerdo con el EOT. } \\
\text { Social: según actividades sociales como } \\
\text { administración pública, escuelas, iglesias, etc. } \\
\text { Patrimonial: según la cercanía a lugares de interés } \\
\text { cultural o arquitectónico. }\end{array}$ \\
\hline
\end{tabular}

Fuente: elaboración propia.

Ya definidos los criterios y su forma de medición, es oportuno indicar la ponderación o importancia de los criterios, dado que carece de validez u objetividad asumir que todos tienen la misma relevancia sobre la decisión. Para esto, se ha utilizado el proceso de análisis jerárquico (Analytic Hierarchy Process AHP, por sus siglas en inglés) desarrollado por Saaty (2014) y consiste en el establecimiento de una secuencia de relaciones lógicas entre los criterios, donde se califica, en escala de jerarquías, la relevancia entre una variable u otra. Las escalas de valoración, definidas por el mismo autor, se representan en la siguiente tabla:

Tabla 4. Escalas de análisis jerárquico

\begin{tabular}{|c|c|c|c|c|c|c|c|c|}
\hline \multicolumn{4}{|c|}{ Valoración más débil } & \multirow[b]{2}{*}{ IGUAL } & \multicolumn{4}{|c|}{ Valoración más fuerte } \\
\hline Extremo & Fuerte & $\begin{array}{c}\text { Moderado } \\
\text { - Alto }\end{array}$ & $\begin{array}{c}\text { Moderado } \\
\text { - Bajo }\end{array}$ & & $\begin{array}{c}\text { Moderado } \\
\text { - Bajo }\end{array}$ & $\begin{array}{c}\text { Moderado } \\
\text { - Alto }\end{array}$ & Fuerte & Extremo \\
\hline $1 / 9$ & $1 / 7$ & $1 / 5$ & $1 / 3$ & 1 & 3 & 5 & 7 & 9 \\
\hline
\end{tabular}

Fuente: Saaty (2014). 
El análisis jerárquico desarrollado para el presente estudio se sintetiza en la Tabla 5. Con base en la escala de valoración representada en la Tabla 4, se analiza la relación entre pares para todos los criterios definidos, midiendo qué tan importante es cada criterio frente al resto de atributos observados. Esto genera una valoración detallada sobre qué ponderación debe ser usada para cada una de estas variables al tomar la decisión.

Estas relaciones se determinaron a partir de las consideraciones subjetivas establecidas por el decisor (Alcaldía de
Tibasosa), al entender que la EMC es un instrumento de apoyo a la decisión. Para comprender de mejor manera los valores de la Tabla 5, a continuación se interpretan los siguientes resultados: al relacionarse los criterios Adecuación del uso del suelo (criterio 2, ubíquese en fila) y Propiedad del terreno del municipio (criterio 1, ubíquese en columna), el criterio 2 tiene una valoración fuertemente moderada-alta frente al criterio 1 ; $\mathrm{y}$, por analogía, la propiedad del terreno del municipio tiene una valoración débilmente moderada-alta frente a la adecuación del uso del suelo (véanse: casilla fila 1 y columna 2 de la Tabla 5).

Tabla 5. Ponderación de criterios mediante AHP

\begin{tabular}{|c|c|c|c|c|c|c|c|c|c|}
\hline $\begin{array}{l}\text { PONDERACIÓN } \\
\text { DE CRITERIOS }\end{array}$ & 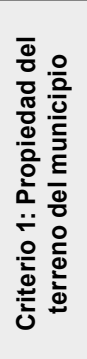 & 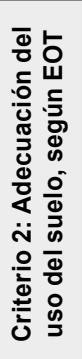 & 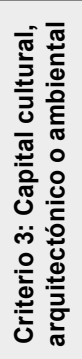 & 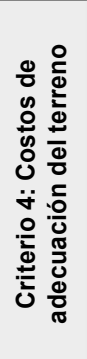 & 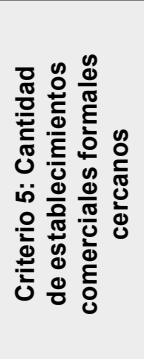 & 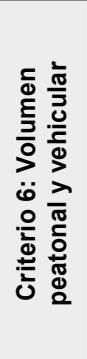 & 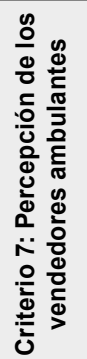 & 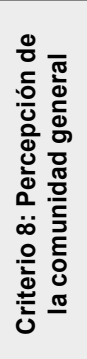 & 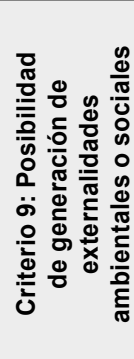 \\
\hline $\begin{array}{c}\text { Criterio 1: Propiedad } \\
\text { del terreno del } \\
\text { municipio }\end{array}$ & 1 & $1 / 5$ & $1 / 5$ & $1 / 5$ & 1 & $1 / 3$ & $1 / 3$ & $1 / 3$ & $1 / 3$ \\
\hline $\begin{array}{l}\text { Criterio 2: Adecuación } \\
\text { del uso del suelo, } \\
\text { según EOT }\end{array}$ & 5 & 1 & 1 & 3 & 5 & 5 & 3 & 3 & 5 \\
\hline $\begin{array}{c}\text { Criterio 3: Capital } \\
\text { cultural, arquitectónico } \\
\text { o ambiental }\end{array}$ & 5 & 1 & 1 & 3 & 5 & 5 & 3 & 3 & 5 \\
\hline $\begin{array}{l}\text { Criterio 4: Costos de } \\
\text { adecuación del terreno }\end{array}$ & 5 & $1 / 3$ & $1 / 3$ & 1 & 5 & 5 & 3 & 3 & 5 \\
\hline $\begin{array}{c}\text { Criterio 5: Cantidad } \\
\text { de establecimientos } \\
\text { comerciales } \\
\text { formales cercanos }\end{array}$ & 1 & $1 / 5$ & $1 / 5$ & $1 / 5$ & 1 & 1 & $1 / 3$ & $1 / 3$ & 1 \\
\hline $\begin{array}{l}\text { Criterio 6: Volumen } \\
\text { peatonal y vehicular }\end{array}$ & 3 & $1 / 5$ & $1 / 5$ & $1 / 5$ & 1 & 1 & $1 / 3$ & $1 / 3$ & 1 \\
\hline
\end{tabular}


Continuación Tabla 5

\begin{tabular}{|c|c|c|c|c|c|c|c|c|c|}
\hline $\begin{array}{l}\text { PONDERACIÓN } \\
\text { DE CRITERIOS }\end{array}$ & 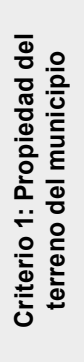 & 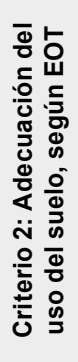 & 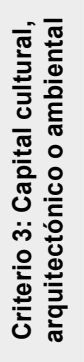 & 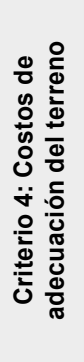 & 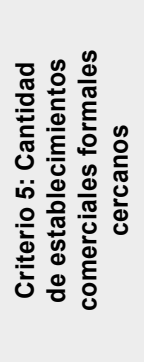 & 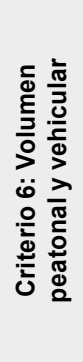 & 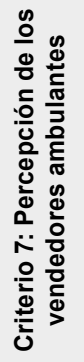 & 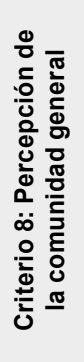 & 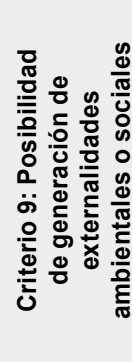 \\
\hline $\begin{array}{l}\text { Criterio 7: Percepción } \\
\text { de los vendedores } \\
\text { ambulantes }\end{array}$ & 3 & $1 / 3$ & $1 / 3$ & $1 / 3$ & 3 & 3 & 1 & 1 & 3 \\
\hline $\begin{array}{l}\text { Criterio 8: } \\
\text { Percepción de la } \\
\text { comunidad general }\end{array}$ & 3 & $1 / 3$ & $1 / 3$ & $1 / 3$ & 3 & 3 & 1 & 1 & 3 \\
\hline $\begin{array}{l}\text { Criterio 9: Posibilidad } \\
\text { de generación de } \\
\text { externalidades } \\
\text { ambientales o sociales }\end{array}$ & 3 & $1 / 5$ & $1 / 5$ & $1 / 5$ & 1 & 1 & $1 / 3$ & $1 / 3$ & 1 \\
\hline
\end{tabular}

Fuente: cálculos propios.

Posterior al cálculo de las escalas por cada par se realiza un proceso de normalización para obtener los resultados generales de ponderación, los cuales son presentados en la Tabla 6. Del análisis jerárquico resulta que los criterios con mayor ponderación para la decisión son: adecuación del uso del suelo, según EOT y capital cultural, arquitectónico o ambiental; les siguen: costos de adecuación del terreno, percepción de los vendedores ambulantes, percepción de la comunidad general, volumen peatonal y vehicular, posibilidad de generación de externalidades ambientales o sociales $\mathrm{y}$ cantidad de establecimientos comerciales formales cercanos, y el criterio con la menor ponderación es propiedad del terreno del municipio.

Estas ponderaciones serán aplicadas a cada uno de los criterios cuando sean medidos para las correspondientes alternativas de forma normalizada. Sumado a lo anterior, a partir de la metodología detallada por Gómez y Barredo (2005), se ha hecho una prueba de consistencia lógica de los datos obtenidos mediante el análisis jerárquico con un balance positivo ${ }^{6}$.

6 La prueba de consistencia se basa en hallar el eigenvector principal y el eigenvector principal normalizado de los datos obtenidos en
el AHP. El resutado de la prueba debe ser menor que 1, para garantizar que los datos sean lógicos y consistentes. Para mayor detalle ver Gómez y Barredo (2005). 
Tabla 6. Ponderación porcentual de los criterios de decisión

\begin{tabular}{cc} 
Criterios & $\begin{array}{c}\text { Ponderación } \\
\text { de criterios }\end{array}$ \\
\hline Criterio 1: Propiedad del terreno del municipio & $3.2 \%$ \\
Criterio 2: Adecuación del uso del suelo, según EOT & $23.9 \%$ \\
Criterio 3: Capital cultural, arquitectónico o ambiental & $23.9 \%$ \\
Criterio 4: Costos de adecuación del terreno & $17.4 \%$ \\
Criterio 5: Cantidad de establecimientos & $3.8 \%$ \\
Criterio 6: Volumen peatonal y vehicular & $4.5 \%$ \\
Criterio 7: Percepción de los vendedores ambulantes & $9.4 \%$ \\
Criterio 8: Percepción de la comunidad general & $9.4 \%$ \\
Criterio 9: Posibilidad de generación de & $4.5 \%$ \\
\hline
\end{tabular}

Fuente: cálculos propios con base en AHP.

Definición del tamaño de muestras para aplicación de instrumentos de recolección de información a vendedores ambulantes y comunidad general

Se han empleado como técnicas para definir el tamaño de las muestras de las poblaciones objetivos para aplicar los instrumentos de recolección de información (entrevistas, para vendedores ambulantes; encuestas, para comunidad general7), los muestreos intencional y por conveniencia, los cuales no son probabilísticos (Otzen \& Manterola, 2017).

El muestreo intencional se fundamenta en que tiene como intención priorizar individuos de la población objeto que pueden contribuir en mayor medida con el estudio en correspondencia (individuos claves). Por ejemplo, para la encuesta de percepción de la comunidad general, los individuos claves, a juicio del equipo investigador, son los comerciantes vecinos del Parque Principal (actual foco en donde se desarrolla la actividad comercial de venta informal), puesto que habitualmente se ven afectados por esta problemática.

En el caso del muestreo por conveniencia, este tiene en cuenta la aceptación de los individuos para involucrarse en la investigación o, en otras palabras, el grado de voluntariedad de los individuos encuestados o entrevistados. La elección de esta técnica se debe a que en esta clase de estudios, es decir, aquellos en los que es evidente un alto grado de disputa de intereses personales y recelo para conceder una opinión, únicamente se ha recolectado la información por la voluntariedad de los individuos participantes en el estudio.

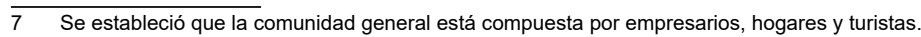


Es por ello que, luego de realizarse el respectivo trabajo de campo, se han aplicado 59 encuestas a la comunidad general y 20 entrevistas a los vendedores ambulantes 8 .

\section{RESULTADOS}

La siguiente tabla muestra las valoraciones de los criterios para cada una de las alternativas propuestas como ubicación idónea de la venta ambulante en Tibasosa. Estas valoraciones se fundamentan en las fuentes de información relacionadas en la Tabla 3 y sus resultados desagregados se presentan para cada criterio en los anexos.

Tabla 7. Consolidación matriz de decisión-valoración de criterios para las alternativas de ubicación de la venta ambulante, municipio de Tibasosa

\begin{tabular}{|c|c|c|c|c|c|c|c|c|c|c|c|}
\hline \multirow[b]{2}{*}{ (VAL } & \multirow[b]{2}{*}{$\begin{array}{l}\text { MATRIZ GENERAL } \\
\text { LORACIÓN DE CRITERIOS) }\end{array}$} & \multicolumn{10}{|c|}{ ALTERNATIVAS - LUGARES } \\
\hline & & 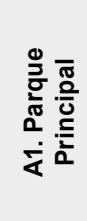 & 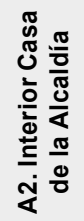 & 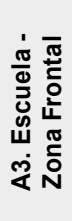 & 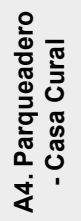 & 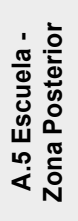 & 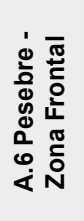 & 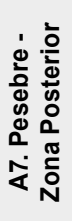 & 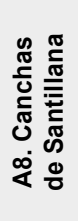 & 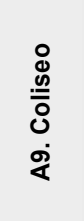 & 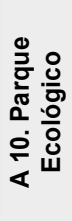 \\
\hline \multirow{7}{*}{ 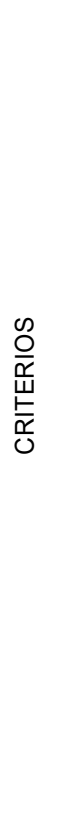 } & $\begin{array}{l}\text { Criterio 1: Propiedad del } \\
\text { terreno del municipio }\end{array}$ & 2 & $\bar{\omega}$ & $\bar{\omega}$ & 2 & $\bar{\omega}$ & $\bar{\omega}$ & $\bar{\omega}$ & के & ๘ & $\bar{\omega}$ \\
\hline & $\begin{array}{l}\text { Criterio 2: Adecuación del } \\
\text { uso del suelo, según EOT }\end{array}$ & 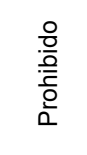 & 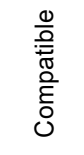 & $\begin{array}{l}\frac{0}{0} \\
\stackrel{0}{0} \\
\stackrel{0}{0} \\
\overline{0} \\
0\end{array}$ & $\begin{array}{l}\frac{0}{0} \\
\text { 竞 } \\
\text { हे } \\
0\end{array}$ & 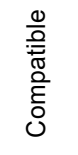 & $\begin{array}{l}\frac{0}{0} \\
\frac{0}{2} \\
\frac{0}{2} \\
\frac{0}{2}\end{array}$ & $\begin{array}{l}\frac{0}{0} \\
\frac{0}{0} \\
\frac{0}{0} \\
\frac{0}{2}\end{array}$ & 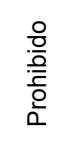 & $\begin{array}{l}\frac{0}{0} \\
\frac{0}{2} \\
\frac{0}{2} \\
\frac{2}{2}\end{array}$ & 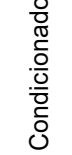 \\
\hline & $\begin{array}{l}\text { Criterio 3: Capital cultural, } \\
\text { arquitectónico o ambiental }\end{array}$ & $\begin{array}{l}\frac{.0}{0} \\
\frac{0}{2}\end{array}$ & $\frac{.0}{0}$ & $\frac{\stackrel{\circ}{\widetilde{\pi}}}{\infty}$ & $\stackrel{\circ}{\stackrel{0}{\pi}}$ & $\stackrel{\circ}{\frac{0}{\infty}}$ & $\frac{.0}{0}$ & $\stackrel{\circ \frac{0}{0}}{\sum^{\infty}}$ & $\frac{\mathrm{O}}{\mathrm{z}}$ & $\frac{\circ}{\bar{z}}$ & $\begin{array}{l}\frac{.0}{2} \\
\stackrel{0}{\Sigma}\end{array}$ \\
\hline & $\begin{array}{l}\text { Criterio 4: Costos de } \\
\text { adecuación del terreno } \\
\text { (pesos colombianos) }\end{array}$ & 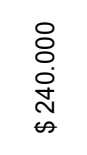 & 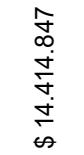 & $\begin{array}{l}m \\
0 \\
o \\
\infty \\
0 \\
0 \\
0 \\
\infty \\
\infty\end{array}$ & 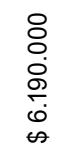 & 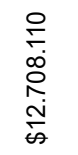 & 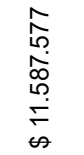 & $\begin{array}{l}\underset{\sim}{\Psi} \\
\underset{\infty}{\infty} \\
\stackrel{\infty}{\infty} \\
\leftrightarrow\end{array}$ & 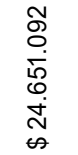 & $\begin{array}{l}\stackrel{P}{f} \\
\dot{f} \\
\vdots \\
\dot{0} \\
0\end{array}$ & 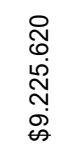 \\
\hline & $\begin{array}{l}\text { Criterio 5: Cantidad } \\
\text { de establecimientos } \\
\text { comerciales formales } \\
\text { cercanos (a menos de } 70 \\
\text { metros de la alternativa) }\end{array}$ & 29 & 21 & 10 & 8 & 3 & 6 & 1 & 4 & 3 & 0 \\
\hline & $\begin{array}{l}\text { Criterio 6: Volumen } \\
\text { peatonal y vehicular }\end{array}$ & 168,5 & 120,7 & 40,2 & 40,2 & 18,7 & 17,8 & 45,3 & 310,1 & 272,9 & 17,3 \\
\hline & $\begin{array}{l}\text { Criterio 7: Percepción de } \\
\text { los vendedores ambulantes }\end{array}$ & 4,60 & 3,44 & 1,65 & 1,78 & 1,25 & 1,80 & 1,60 & 1,95 & 1,55 & 1,45 \\
\hline
\end{tabular}

$8 \quad$ La muestra de los vendedores ambulantes representa el $46.5 \%$ de la base de datos de vendedores ambulantes dispuesta por la Alcaldía. 


\begin{tabular}{|c|c|c|c|c|c|c|c|c|c|c|}
\hline \multirow[b]{2}{*}{$\begin{array}{c}\text { MATRIZ GENERAL } \\
\text { (VALORACIÓN DE CRITERIOS) }\end{array}$} & \multicolumn{10}{|c|}{ ALTERNATIVAS - LUGARES } \\
\hline & 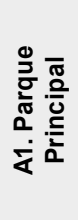 & 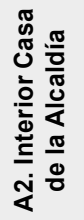 & 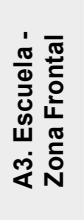 & 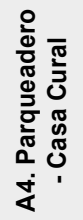 & 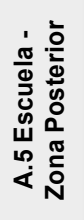 & 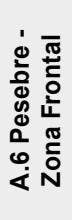 & 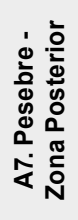 & 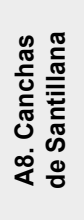 & 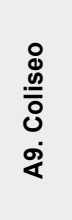 & 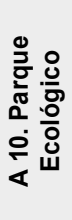 \\
\hline $\begin{array}{l}\text { Criterio 8: Percepción de } \\
\text { la comunidad general }\end{array}$ & 2,93 & 3,24 & 3,32 & 3,32 & 2,67 & 3,15 & 2,99 & 2,89 & 2,67 & 2,81 \\
\hline $\begin{array}{l}\text { Criterio 9: Posibilidad } \\
\text { de generación de } \\
\text { externalidades } \\
\text { ambientales o sociales }\end{array}$ & $\frac{\pi}{\frac{\pi}{4}}$ & $\stackrel{\frac{\pi}{*}}{\frac{\pi}{\sigma}}$ & $\frac{\pi}{\frac{\pi}{\alpha}}$ & $\stackrel{\frac{\pi}{\pi}}{\tilde{\Phi}}$ & $\frac{\frac{\pi}{\sigma}}{\sum}$ & $\frac{\frac{\pi}{\overline{0}}}{\sum}$ & $\frac{-\frac{\pi}{0}}{\sum^{\infty}}$ & $\frac{\frac{\pi}{\pi}}{\infty}$ & $\frac{. \pi}{\pi}$ & $\frac{\sqrt[\pi]{\pi}}{\infty}$ \\
\hline
\end{tabular}

Fuente: elaboración propia, a partir de las fuentes de información detalladas para cada uno de los criterios en la Tabla 3.

Los datos expuestos en la tabla anterior deben normalizarse, pues de este modo se procede con la comparación estandarizada de las alternativas -según los criterios de decisión-, y con la regla de decisión. El primer paso para la normalización de los datos consiste en volver nominales las valoraciones de todos los criterios; en los anexos 1, 2, 3 y 6 se especifican las escalas de medición para los criterios limitantes (criterios 1, 2, 3 y 9), puesto que no son cuantificables a primera vista.

Tabla 8. Valoración nominal de los criterios limitantes para las alternativas de ubicación de la venta ambulante, municipio de Tibasosa

\begin{tabular}{|c|c|c|c|c|c|c|c|c|c|c|c|}
\hline & & \multicolumn{10}{|c|}{ ALTERNATIVAS - LUGARES } \\
\hline & & 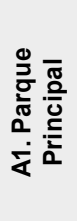 & 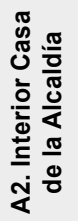 & 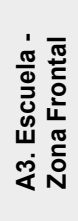 & 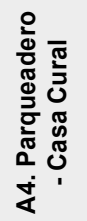 & 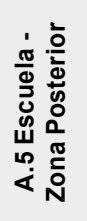 & 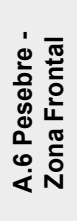 & 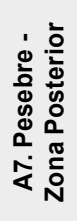 & 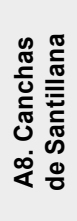 & $\begin{array}{l}\stackrel{\circ}{8} \\
. \underline{0} \\
0 \\
\dot{0}\end{array}$ & 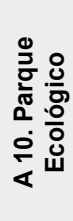 \\
\hline \multirow{4}{*}{ 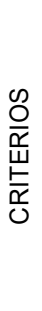 } & $\begin{array}{l}\text { Criterio 1: Propiedad del } \\
\text { terreno del municipio }\end{array}$ & 0 & 1 & 1 & 0 & 1 & 1 & 1 & 1 & 1 & 1 \\
\hline & $\begin{array}{l}\text { Criterio 2: Adecuación del } \\
\text { uso del suelo, según EOT }\end{array}$ & 0 & 2 & 2 & 2 & 2 & 0 & 0 & 0 & 0 & 1 \\
\hline & $\begin{array}{l}\text { Criterio 3: Capital cultural, } \\
\text { arquitectónico o ambiental }\end{array}$ & 1 & 1 & 2 & 2 & 2 & 1 & 1 & 3 & 3 & 1 \\
\hline & $\begin{array}{l}\text { Criterio 9: Posibilidad de } \\
\text { generación de externalidades } \\
\text { ambientales o sociales }\end{array}$ & 0 & 0 & 0 & 2 & 1 & 1 & 1 & 2 & 2 & 2 \\
\hline
\end{tabular}

Fuente: elaboración propia. 
El paso siguiente es aplicar la Ecuación 1 , la cual calcula el valor normalizado del criterio $j$ para la alternativa $l$, como la división de la valoración nominal del criterio $j$ para la alternativa $l\left(X_{j l}\right)$ entre la sumatoria de la valoración nominal del criterio $j$ para todas las alternativas -de la 1 a la $l-\left(\sum_{1}^{l} X_{j,(1 \ldots l)}\right)$, multipli- cada por la ponderación porcentual del criterio $j\left(P_{j}\right)$. La ecuación detallada hace que el valor normalizado del criterio $j$ para la alternativa $l$ sea mayor que 0 y menor que 1 ; estas restricciones se justifican porque $X_{j l}$ siempre será menor que $\sum_{1}^{l} X_{j,(1 \ldots l)}$, y porque $X_{j l}$ siempre será con valor positivo.

$$
\begin{aligned}
& \text { Valor Normalizado } X_{j l}=\frac{X_{j l}}{\sum_{1}^{l} X_{j,(1 . . l)}} \times P_{j} \\
& \text { donde, } 0<\text { Valor Normalizado } X_{j l}<1
\end{aligned}
$$

Con respecto a los criterios 4 (costos de adecuación del terreno) y 5 (cantidad de establecimientos comerciales formales cercanos), previamente se han tenido que transformar sus valores, en razón a que un alto valor sobre cada criterio le representa una desventaja para cualquier alternativa. Así, la transformación posibilita que la alternativa que cuenta con una alta cantidad de establecimientos comerciales o que comprometa elevados costos de adecuación, obtenga un bajo valor normalizado.
La transformación de los valores del criterio 4, para cada una de las alternativas, sigue la Ecuación 2. Por ejemplo, la transformación del valor del criterio 4 para la alternativa $l$ se opera como la resta del valor máximo del criterio 4 (24 651092 pesos, que es el correspondiente para la alternativa 8: canchas de Santillana) menos su respectivo valor.

$$
\text { Transformación } X_{4 l}=\$ 24.651 .092-X_{4 l}
$$

En el criterio 5 la transformación de los valores para cada una de las alternativas se fundamenta en la Ecuación 3. Por ejemplo, la transformación del valor del criterio 5 para la alternativa $l$ se calcula como la resta del valor máximo del criterio 5 (29 establecimientos comerciales formales cercanos, que es el correspondiente para la alternativa 1: Parque Principal) menos su respectivo valor.

$$
\text { Transformación } X_{5 l}=29-X_{5 l}
$$


Después de la normalización de los valores de los criterios de decisión se aplica la Ecuación 4, con el fin de calcular el puntaje de valoración normalizada para cada alternativa. La ecuación para la alternativa $l$ corresponde a la sumatoria de los valores normalizados de todos los criterios que hacen parte de la misma alternativa - del 1 al $j-\left(\sum_{1}^{j} X_{(1 \ldots j), l}\right)$ :

Puntaje Valoración Normalizada Alternativa $l=\sum_{1}^{j} X_{(1 \ldots j), l}$

donde, $0<$ Puntaje Valoración Normalizada Alternativa $l<1$

Del proceso operativo descrito se ha determinado el puntaje de valoración normalizada para cada una de las alternativas. El parqueadero de la casa cural (alternativa 4) ha sido la alternativa con el mayor puntaje de valoración norma- lizada $(0,136)$. Le siguen, escuela- zona frontal $(0,127)$, escuela-zona posterior $(0,123)$ y Parque Principal $(0,116)$. Las demás alternativas obtuvieron un puntaje menor que 0,110 (Tabla 9).

Tabla 9. Normalización de valores de la matriz de decisión, criterios y alternativas para la ubicación de la venta ambulante, municipio de Tibasosa

\begin{tabular}{|c|c|c|c|c|c|c|c|c|c|c|c|}
\hline \multirow{2}{*}{\multicolumn{2}{|c|}{$\begin{array}{l}\text { MATRIZ GENERAL DE } \\
\text { VALORACIÓN DE CRITERIOS } \\
\text { (DATOS NORMALIZADOS) }\end{array}$}} & \multicolumn{10}{|c|}{ ALTERNATIVAS - LUGARES } \\
\hline & & 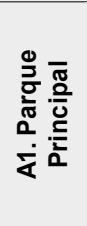 & 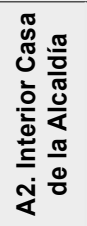 & 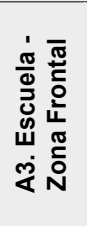 & 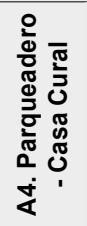 & 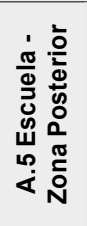 & 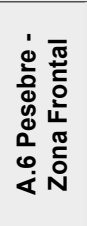 & 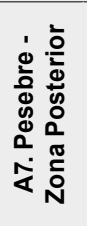 & 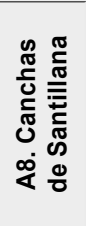 & $\begin{array}{l}\stackrel{0}{\Phi} \\
. \underline{0} \\
0 \\
\dot{0} \\
\dot{8}\end{array}$ & 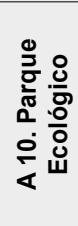 \\
\hline \multirow{8}{*}{ 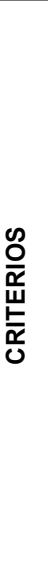 } & $\begin{array}{l}\text { Criterio 1: Propiedad del } \\
\text { terreno del municipio }\end{array}$ & 0,000 & 0,004 & 0,004 & 0,000 & 0,004 & 0,004 & 0,004 & 0,004 & 0,004 & 0,004 \\
\hline & $\begin{array}{l}\text { Criterio 2: Adecuación del } \\
\text { uso del suelo, según EOT }\end{array}$ & 0,000 & 0,053 & 0,053 & 0,053 & 0,053 & 0,000 & 0,000 & 0,000 & 0,000 & 0,027 \\
\hline & $\begin{array}{l}\text { Criterio 3: Capital cultural, } \\
\text { arquitectónico o ambiental }\end{array}$ & 0,014 & 0,014 & 0,028 & 0,028 & 0,028 & 0,014 & 0,014 & 0,042 & 0,042 & 0,014 \\
\hline & $\begin{array}{l}\text { Criterio 4: Costos de } \\
\text { adecuación del terreno }\end{array}$ & 0,029 & 0,012 & 0,018 & 0,022 & 0,014 & 0,016 & 0,020 & 0,000 & 0,023 & 0,019 \\
\hline & $\begin{array}{c}\text { Criterio 5: Cantidad de } \\
\text { establecimientos comerciales } \\
\text { formales cercanos }\end{array}$ & 0,000 & 0,001 & 0,003 & 0,004 & 0,005 & 0,004 & 0,005 & 0,005 & 0,005 & 0,005 \\
\hline & $\begin{array}{l}\text { Criterio 6: Volumen } \\
\text { peatonal y vehicular }\end{array}$ & 0,007 & 0,005 & 0,002 & 0,002 & 0,001 & 0,001 & 0,002 & 0,013 & 0,012 & 0,001 \\
\hline & $\begin{array}{l}\text { Criterio 7: Percepción de } \\
\text { los vendedores ambulantes }\end{array}$ & 0,021 & 0,015 & 0,007 & 0,008 & 0,006 & 0,008 & 0,007 & 0,009 & 0,007 & 0,006 \\
\hline & $\begin{array}{l}\text { Criterio 8: Percepción de } \\
\text { la comunidad general }\end{array}$ & 0,009 & 0,010 & 0,010 & 0,010 & 0,008 & 0,010 & 0,009 & 0,009 & 0,008 & 0,009 \\
\hline
\end{tabular}




\begin{tabular}{|c|c|c|c|c|c|c|c|c|c|c|}
\hline \multirow[b]{2}{*}{$\begin{array}{l}\text { MATRIZ GENERAL DE } \\
\text { VALORACIÓN DE CRITERIOS } \\
\text { (DATOS NORMALIZADOS) }\end{array}$} & \multicolumn{10}{|c|}{ ALTERNATIVAS - LUGARES } \\
\hline & 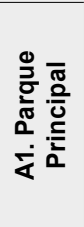 & 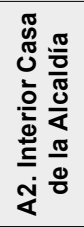 & 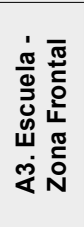 & 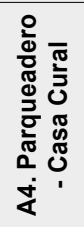 & 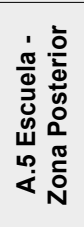 & 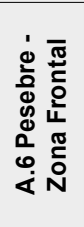 & 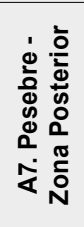 & 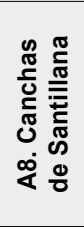 & 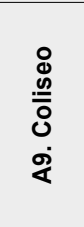 & 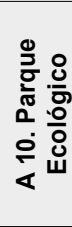 \\
\hline $\begin{array}{l}\text { Criterio 9: Posibilidad de } \\
\text { generación de externalidades } \\
\text { ambientales o sociales }\end{array}$ & 0,000 & 0,000 & 0,000 & 0,008 & 0,004 & 0,004 & 0,004 & 0,008 & 0,008 & 0,008 \\
\hline $\begin{array}{c}\text { TOTAL (Puntaje de } \\
\text { valoración normalizada) }\end{array}$ & 0,081 & 0,116 & 0,127 & 0,136 & 0,123 & 0,061 & 0,066 & 0,090 & 0,109 & 0,093 \\
\hline
\end{tabular}

Fuente: cálculos propios.

\section{DISCUSIÓN}

Leyva (2010) señala cuatro posibles reglas de decisión que orientan la finalidad de esta: la primera de ellas se refiere a identificar una única alternativa o a establecer un número reducido (muestra) de las alternativas que mayor coherencia demuestren con el objetivo planteado; la segunda corresponde a una clasificación ordenada de las alternativas, de acuerdo con su adaptabilidad con los criterios planteados; la tercera clasifica o estratifica las alternativas según su adherencia a algunos criterios específicos definidos por el decisor; y la última categoría definida por el autor, se trata de una descripción con mayor subjetividad de las características de cada alternativa, que ofrece al decisor una metodología más flexible en la elección. Según el objeto de la presente investigación, goza de mayor validez el desarrollo del proceso de EMC a partir de las tres primeras clasificaciones.
Con respecto a la alternativa parqueadero de la casa cural -la de mayor puntaje de valoración normalizada-, aunque el terreno no es de propiedad del municipio ${ }^{9}$, esta opción representa resultados favorables en los demás criterios:

- Según el EOT, es compatible la adecuación del uso del suelo.

- Es bajo el impacto que genera al capital cultural, arquitectónico o ambiental de Tibasosa.

- No son altos los costos de adecuación del terreno (es la tercera alternativa con los menores costos).

- Comparablemente, los vendedores ambulantes prefieren el parqueadero de la casa cural que las zonas frontal y posterior de la escuela, la zona posterior en donde se ubica el pesebre en las fiestas decembrinas, el coliseo y el Parque Ecológico.

9 Es el criterio con la menor ponderación: $3.2 \%$ (Tabla 6). 
- La comunidad general (hogares, empresarios y turistas) prefiere la alternativa, en comparación con el Parque Principal, la zona posterior de la escuela, la zona posterior en donde se ubica el pesebre en las fiestas decembrinas, las canchas de santillana, el coliseo y el Parque Ecológico.

- Comparablemente, es mayor su volumen peatonal y vehicular que el de la zona posterior de la escuela, la zona frontal en donde se ubica el pesebre en las fiestas decembrinas y el Parque Ecológico.

- Es baja su posibilidad de generar externalidades ambientales o sociales.

- Es menor la cantidad de establecimientos comerciales formales cercanos a 70 metros de la alternativa seleccionada, en contraste con el Parque Principal, el interior de la casa de la Alcaldía y la zona frontal de la escuela.

En vista de los resultados analizados sobre los criterios de selección para el parqueadero de la casa cural, este sitio es la alternativa idónea para que la Alcaldía ubique permanentemente la venta ambulante, dado que responde positivamente a los criterios de selección tenidos en cuenta; sobre todo, aquellos que tuvieron mayor relevancia en la decisión (criterios 2, 3 y 4).
Es comprensible que los vendedores ambulantes, como actores directos de la actividad comercial en discusión, manifiesten su preferencia por el Parque Principal del municipio para ejercer su proyecto económico, pues es el principal escenario del desarrollo urbano y turístico de Tibasosa. No obstante, como el fenómeno en estudio abarca otros ámbitos sociales y debe propiciar la regulación del espacio público, es necesario considerar los puntos de vista de los otros actores vinculados: de la administración municipal, como actor responsable de la regulación sobre el espacio público; de los hogares, como actores convecinos y potenciales compradores de los vendedores ambulantes; de los empresarios, como competidores de la actividad comercial; y de los turistas, como potenciales compradores. En ese sentido, el parqueadero de la casa cural también se adecúa a la perspectiva pluralista de la venta ambulante, con el objeto de beneficiar a todos los actores.

\section{CONCLUSIONES}

En este documento se ha propuesto una metodología de pertinencia en política pública territorial, para atender las problemáticas de espacio público asociadas al fenómeno de la venta informal en escenarios urbanos. Si bien la multidimensionalidad del fenómeno ha enfrentado de forma paralela (1) la necesidad de desarrollar el proyecto productivo de una comunidad marginada social y económicamente, frente 
a (2) la obligación constitucional de preservar el interés general sobre el particular en el uso del espacio público, la metodología permitió una aproximación a esta dicotomía con integralidad. En efecto, se abordaron diversos criterios que acogían los diferentes intereses y contextos político-administrativos, sociales, culturales y económicos aplicados a diez alternativas de reubicación.

Específicamente, gracias a la aplicación de la evaluación multicriterio (EMC), se ha identificado que, con la rigurosidad técnica requerida por el fenómeno, la alternativa más idónea para que la Alcaldía de Tibasosa ubique permanentemente la venta ambulante en el municipio es el parqueadero de la casa cural. Según los resultados, excepto por no ser este inmueble de propiedad del municipio, esta alternativa registra un balance positivo sobre los demás criterios de decisión (sobre todo aquellos de mayor ponderación o relevancia), lo cual posibilita que todos los actores involucrados (vendedores ambulantes, empresarios, hogares, turistas y administración municipal) sean beneficiados con la alternativa recomendada.

Sin embargo, en cuanto al ejercicio de la política pública, ninguna alternativa es determinística. La autoridad local vigente goza de autonomía para escoger la alternativa que le resulte más conveniente, debido a su potestad de actor decisor y ejecutor. Además, los resultados del presente estudio son un insumo de apoyo a la decisión, que garantizan objetividad en esta.

Por último, cabe aclarar que este documento no tiene la intención de evaluar la gestión efectuada por parte de la administración municipal. Su finalidad ha sido de tipo técnico e investigativo, para lo cual se basó en la descripción de la aplicación de la metodología considerada, sobre un fenómeno como la venta ambulante, que posee una perspectiva pluralista y una problemática amplia y progresiva.

\section{CONTRIBUCIÓN DE LOS AUTORES}

El presente artículo es resultado del trabajo conjunto de los autores.

\section{AGRADECIMIENTOS}

Los autores agradecen a la administración municipal del periodo institucional 2016-2019, Unidad y Compromiso por Tibasosa, por sus apoyos logísticos y técnicos prestados al estudio base; a los vendedores ambulantes, empresarios, habitantes y turistas que participaron en la aplicación de los instrumentos de recolección de información formulados; y a los pares evaluadores, por sus recomendaciones.

\section{FINANCIAMIENTO}

La presente investigación no contó con financiamiento. 
DECLARACIÓN CONFLICTO DE la intención del artículo es de tipo INTERESES académico e investigativo. Los mismos

Los autores declaran que no existe conautores asumen la responsabilidad sobre flicto de intereses de ninguna índole; las opiniones contenidas en el artículo. 


\section{REFERENCIAS}

[1] Alcaldía Municipal de Tibasosa (2019). Estudio previo del número de proceso PC-MT-CD-038-2019. https://www.contratos.gov.co/consultas/detalleProceso. do?numConstancia=19-12-9032597

[2] Becker, K. F. (2004). The Informal Economy. Swedish International Development Cooperation Agency.

[3] Bhowmik, S. K. (2005). Street Vendors in Asia: A Review. Economic and Political Weekly, 40(22), 2256-2264.

[4] Bhowmik, S. K. (2010). Street Vendors in the Global Urban Economy. Routledge Taylor \& Francis Group.

[5] Bromley, R. (2000). Street Vending and Public Policy: A Global Review. International Journal of Sociology and Social Policy, 20(1-2). https://doi. org/10.1108/01443330010789052

[6] Castañeda, A. \& García, J. (2007). Hábitat y espacio público: el caso de los vendedores informales en el espacio público de Bogotá. Fundación Cultura Javeriana de Artes Gráficas JAVEGRAF.

[7] Chen, M. A. (2012). The Informal Economy: Definitions, Theories and Policies. Women in Informal Economy Globalizing and Organizing, WIEGO. Working Paper, 1.

[8] Cimoli, M., Primi, A. \& Pugno, M. (2006). Un modelo de bajo crecimiento: la informalidad como restricción estructural. Revista de la CEPAL, (88).

[9] Congreso de la República de Colombia. (2016). Ley 1801. Imprenta Nacional.

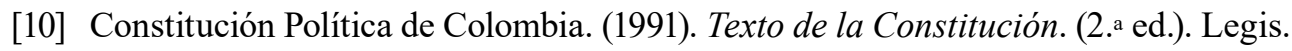

[11] Delgado, P., Cárdenas, A. \& García, J. (2008). Espacio público y derecho a la ciudad: la política del espacio público físico y la venta informal en Bogotá. Fundación Cultura Javeriana de Artes Gráficas JAVEGRAF.

[12] Deore, P. \& Lathia, S. (2019). Streets as Public Spaces: Lessons from Street Vending in Ahmedabad, India. Urban Planning, 4(2), 138-153. https://doi. org/10.17645/up.v4i2.2058 
[13] De Soto, H. (2000). El misterio del capital: por qué el capitalismo triunfa en Occidente y fracasa en el resto del mundo. El Comercio.

[14] De Soto, H., Ghersi, E. \& Guibellini, M. (1986). El otro sendero: la revolución informal. El Barranco.

[15] Donovan, M. (2004). La guerra por el espacio público en Bogotá: la "recuperación" del espacio público y su impacto sobre los vendedores ambulantes. Territorios, (12), 109-146.

[16] Elgin, C. \& Oyvat, C. (2013). Lurking in the Cities: Urbanization and the Informal Economy. Structural Change and Economic Dynamics, 27, 36-47. https://doi. org/10.1016/j.strueco.2013.06.003

[17] Feige, E. (1990). Defining and Estimating Underground and Informal Economies: The New Institucional Economics Approach. World Development, 18(7), 9891002. https://doi.org/10.1016/0305-750X(90)90081-8

[18] Ghersi, E. (1997). The Informal Economy in Latin America. Cato Journal, 17(1), 99-108.

[19] Godfrey, P. (2011). Toward a Theory of the Informal Economy. The Academic of Management Annals, 5(1), 231-277. https://doi.org/10.5465/19416520.2011.585818

[20] Gómez, M. \& Barredo, J. (2005). Sistemas de información geográfica y evaluación multicriterio en la ordenación del territorio. RA-MA.

[21] Gramsci, A. (1971). Selections from the Prison Notebooks. In Q. Hoare \& N. Smith (Eds.). International Publishers.

[22] Green, M. (2002). Gramsci Cannot Speak: Presentations and Interpretations of Gramsci's Concept of the Subaltern. Rethinking Marxism, 14(3), 1-24. https://doi. org $/ 10.1080 / 089356902101242242$

[23] Haase, M., Becker, I., \& Pick, D. (2018). Alternative Economies as Marketing Systems? The Role of Value Creation and the Criticism of Economic Growth. Journal of Macromarketing, 38(1), 57-72. https://doi.org/10.1177/0276146717728776

[24] Hart, K. (1973). Informal Income Opportunities and Urban Employment in Ghana. Journal of Modern African Studies, 11(1), 61-89.

[25] Jiménez, D. (2012). La informalidad laboral en América Latina: ¿explicación estructuralista o institucionalista? Cuadernos de Economía, 31(58), 113-143. 
[26] Leyva, J. C. (2010). Métodos de ordenamiento multicriterio. Plaza y Valdés.

[27] Maloney, W. (2004). Informality Revisited. World Development, 32(7), 1159-1178. https://doi.org/10.1016/j.worlddev.2004.01.008

[28] Martínez, L., Short, J. R. \& Estrada, D. (2017). The Urban Informal Economy: Street Vendors in Cali, Colombia. Cities, 66, 34-43. https://doi.org/10.1016/j. cities.2017.03.010

[29] Otzen, T. \& Manterola, C. (2017). Técnicas de muestreo sobre una población a estudio. International Journal of Morphology, 35(1), 227-232.

[30] Policastro, B. \& Rivero, E. (s.f.). Las relaciones de intercambio en el mundo de la venta ambulante. $7 .^{\circ}$ Congreso Nacional de Estudios del Trabajo, Asociación Argentina de Especialistas en Estudios del Trabajo, Buenos Aires.

[31] Portes, A. \& Haller, W. (2004). La economía informal. CEPAL, Serie Políticas Sociales.

[32] Romero, S. (1996). Manual para la toma de decisiones multicriterio. Instituto Latinoameticano y del Caribe de Planificación Económica y Social ILPES, Dirección de Proyectos y Programas de Inversión. https://repositorio.cepal.org/ handle/11362/30558

[33] Romero, S. B. \& Charles, J. (1997). Decisiones multicriterio. Fundamentos teóricos y utilización práctica. Universidad de Alcalá.

[34] Saaty, T. (2014). Toma de decisiones para líderes. El proceso analítico jerárquico la toma de decisiones en un mundo complejo. University of Pittsburgh. www. rwspublications.com

[35] Sarkar, D. \& Kundu, K. (2018). The Overlap Spaces of Alternative Economy and Subaltern Businesses: A Study of Emigrant Peddlers. Journal of Economic Structures, 7(30). https://oi.org/10.1186/s40008-018-0128-9

[36] Spivak, G. (2000). The New Subaltern: A Silent Interview. In V. Chaturvedi (ed), Mapping Subaltern Studies and the Postcolonial (pp. 321-334). Verso.

[37] Stan, L., \& Stefanescu, F. (2018). Pro and Against Informal Economy. Oradea Journal of Business and Economics, 3(2), 78-85.

[38] Tafti, M. T. (2020). Assembling Street Vending. Urban Studies, 57(9), 1887-1902. https://doi.org/10.1177/ 0042098019856864 


\section{ANEXOS}

Anexo 1. Escala de medición criterio 1: Propiedad del terreno del municipio

\begin{tabular}{cc}
\hline Valor & Puntuación \\
Sí & 1 \\
No & 0 \\
\hline
\end{tabular}

Fuente: elaboración propia.

Anexo 2. Escala de medición criterio 2: Adecuación del uso del suelo, según EOT

\begin{tabular}{cc}
\hline Valor & Puntuación \\
\hline Uso principal & 3 \\
Uso compatible & 2 \\
Uso condicionado & 1 \\
Uso prohibido & 0 \\
\hline
\end{tabular}

Fuente: elaboración propia.

Anexo 3. Escala de medición criterio 3: Capital cultural, arquitectónico o ambiental

\begin{tabular}{cc}
\hline Valor & Puntuación \\
\hline Nulo & 3 \\
Bajo & 2 \\
Medio & 1 \\
Alto & 0 \\
\hline
\end{tabular}

Fuente: elaboración propia.

Anexo 4. Explicación de resultados ponderados del criterio 6: Volumen peatonal y vehicular

\begin{tabular}{|c|c|c|c|c|c|c|c|c|c|}
\hline \multicolumn{2}{|c|}{ A1. Parque Principal } & \multicolumn{2}{|c|}{$\begin{array}{l}\text { A2. Interior Casa } \\
\text { de la Alcaldía }\end{array}$} & \multicolumn{2}{|c|}{$\begin{array}{l}\text { A3. Escuela - } \\
\text { Zona Frontal }\end{array}$} & \multicolumn{2}{|c|}{$\begin{array}{l}\text { A4. Parqueadero } \\
\text { - Casa Cural }\end{array}$} & \multicolumn{2}{|c|}{$\begin{array}{c}\text { A.5 Escuela - Zona } \\
\text { Posterior }\end{array}$} \\
\hline Peatonal & Vehicular & Peatonal & Vehicular & Peatonal & Vehicular & Peatonal & Vehicular & Peatonal & Vehicular \\
\hline 230 & 25 & 133 & 92 & 51 & 15 & 51 & 15 & 19 & 18 \\
\hline \multicolumn{2}{|c|}{168,5} & \multicolumn{2}{|c|}{120,7} & \multicolumn{2}{|c|}{40,2} & \multicolumn{2}{|c|}{40,2} & \multicolumn{2}{|c|}{18,7} \\
\hline \multicolumn{2}{|c|}{$\begin{array}{l}\text { A.6 Pesebre - } \\
\text { Zona Frontal }\end{array}$} & \multicolumn{2}{|c|}{$\begin{array}{l}\text { A7. Pesebre - Zona } \\
\text { Posterior }\end{array}$} & \multicolumn{2}{|c|}{$\begin{array}{l}\text { A8. Canchas } \\
\text { de Santillana }\end{array}$} & \multicolumn{2}{|c|}{ A9. Coliseo } & \multicolumn{2}{|c|}{$\begin{array}{l}\text { A 10. Parque } \\
\text { Ecológico }\end{array}$} \\
\hline $\begin{array}{l}\text { Peatonal } \\
19\end{array}$ & $\begin{array}{l}\text { Vehicular } \\
15\end{array}$ & $\begin{array}{l}\text { Peatonal } \\
51\end{array}$ & $\begin{array}{l}\text { Vehicular } \\
32\end{array}$ & $\begin{array}{c}\text { Peatonal } \\
128\end{array}$ & $\begin{array}{c}\text { Vehicular } \\
735\end{array}$ & $\begin{array}{l}\text { Peatonal } \\
89\end{array}$ & $\begin{array}{l}\text { Vehicular } \\
702\end{array}$ & $\begin{array}{l}\text { Peatonal } \\
23\end{array}$ & $\begin{array}{c}\text { Vehicular } \\
4\end{array}$ \\
\hline \multicolumn{2}{|c|}{17,8} & \multicolumn{2}{|c|}{45,3} & \multicolumn{2}{|c|}{310,1} & \multicolumn{2}{|c|}{272,9} & \multicolumn{2}{|c|}{17,3} \\
\hline
\end{tabular}

Fuente: elaboración propia con base en estudio de conteos peatonales y vehiculares. 
Anexo 5. Escala de medición criterios 7 y 8: Percepción de los vendedores ambulantes y percepción de la comunidad general

\begin{tabular}{cc}
\hline Valor & Puntuación \\
\hline Muy Baja & 1 \\
Baja & 2 \\
Media & 3 \\
Alta & 4 \\
Muy Alta & 5 \\
\hline
\end{tabular}

Fuente: elaboración propia.

Anexo 6. Escala de medición criterio 9: Posibilidad de generación de externalidades ambientales o sociales

\begin{tabular}{cc}
\hline Valor & Puntuación \\
\hline Nula & 3 \\
Baja & 2 \\
Media & 1 \\
Alta & 0 \\
\hline
\end{tabular}

Fuente: elaboración propia. 